\section{Anaerobic Production of Methanethiol and Other Compounds by Brassica Vegetables}

\author{
Charles F. Forney ${ }^{1}$ and Michael A. Jordan ${ }^{2}$ \\ Agriculture and Agri-Food Canada, Atlantic Food and Horticulture Research \\ Centre, 32 Main Street, Kentville, N.S., B4N 1J5, Canada
}

Additional index words. Dimethyl disulfide, dimethyl trisulfide, anaerobic metabolism, ethanol, broccoli, pak choi, cabbage, broccoflower, kale, Brussels sprouts, rutabaga, cauliflower, kohlrabi, Brassica oleracea, Brassica napus, Brassica rapa

\begin{abstract}
Methanethiol (MT) is a volatile compound responsible for the unpleasant odor evolved when fresh broccoli (Brassica oleracea $\mathbf{L}$., Italica group) is held under anaerobic conditions. Inductive atmospheres can develop in storage, transportation containers, or modified atmosphere packages, resulting in reduced quality. To determine if related vegetables are capable of producing MT, 12 different vegetables from the genus Brassica were cut into ready-to-eat forms. Fifty-gram samples were sealed in 500-mL glass jars and flushed with $\mathrm{N}_{2}$. After $24 \mathrm{~h}$ in the dark at $20^{\circ} \mathrm{C}$, headspace samples from the jars were analyzed for MT and other volatiles. Headspace concentration of MT was greatest in broccoli florets, followed by pak choi (Brassica rapa L., Chinensis group) leaf blades, savoy cabbage (Brassica oleracea L., Capitata group), broccoflower (Brassica oleracea L., Botrytis group), and green and red cabbage (Brassica oleracea L., Capitata group). Broccoli stems, kale (Brassica oleracea L., Acephala group), Brussels sprouts (Brassica oleracea $\mathrm{L}$., Gemmifera group), pak choi petioles, rutabaga (Brassica napus L., Napobrassica group) root, cauliflower (Brassica oleracea L., Botrytis group) florets, Chinese cabbage (Brassica rapa L., Pekinensis group), and kohlrabi (Brassica oleracea L., Gongylodes group) tubers produced $<3 \%$ of the MT produced by broccoli florets. Green tissues appeared to have a greater capacity to produce MT than nongreen tissues. Anaerobic production of $\mathrm{CO}_{2}$ and ethanol did not relate to the vegetable's ability to produce MT. The production of dimethyl disulfide (DMDS) and dimethyl trisulfide (DMTS) were also induced by the anaerobic conditions. Green cabbage produced the greatest concentration of DMDS, followed by savoy cabbage and broccoli florets. Production of DMTS was similar to the pattern observed for MT, but DMDS production was not highly correlated with MT production.
\end{abstract}

Broccoli florets held in atmospheres of $>10 \% \mathrm{CO}_{2}$ and $<0.5 \% \mathrm{O}_{2}$ produce an unpleasant odor (Ballantyne et al., 1988; Forney and Rij, 1991; Kasmire et al., 1974). The primary chemical responsible for this objectionable odor has been identified as methanethiol (MT) (Forney et al., 1991; Hansen et al., 1992). In addition, dimethyl disulfide (DMDS) and dimethyl trisulfide (DMTS) may contribute to this unpleasant odor. Atmospheres that induce broccoli to produce MT may develop in storage, transportation containers, or modified atmosphere packages (MAP). Production of MT

Received for publication 6 July 1998. Accepted for publication 5 Nov. 1998. Contribution No. 2188 of the Atlantic Food \& Horticulture Research Centre, Agriculture and Agri-Food Canada. We thank Charles Thompson, Extension Vegetable Specialist, and Pansy Brydon for supplying freshly harvested vegetables for this study, Dr. Robert Stark for assistance in shredding cabbage, and Dr. K.B. McRae for statistical advice. The cost of publishing this paper was defrayed in part by the payment of page charges. Under postal regulations, this paper therefore must be hereby marked advertisement solely to indicate this fact.

${ }^{1}$ Storage Physiologist.

${ }^{2} \mathrm{GC}-\mathrm{MS}$ Technician. cabbage; 'Jade Cross E' and 'Valient' Brussels sprouts; 'Alta Sweet', 'Lauratian', and 'York' rutabaga; and 'Early White Vienna' kohlrabi were obtained from experimental plots at the Kentville Research Centre, Nova Scotia, or from commercial growers. Kale, Chinese cabbage, pak choi, red cabbage, savoy cabbage, and Brussels sprouts of unknown cultivars were obtained from local markets. In addition to these vegetables used to measure anaerobic induction of volatiles, each vegetable was obtained from local markets to measure volatiles present under aerobic conditions to serve as controls. Whenever possible, vegetables were used the day of harvest or on the day of purchase, in the case of those obtained from local markets. Plant tissue from three different plants of each cultivar were sampled separately for volatile production.

Broccoli, cauliflower, and broccoflower heads were cut into individual florets with a length and diameter of $<40 \mathrm{~mm}$. In addition, broccoli stems were cut into transverse slices $10 \mathrm{~mm}$ thick. Cabbage heads were shredded into pieces $5 \mathrm{~mm}$ wide, and kale and pak choi leaf blades were cut into pieces $50 \times 50 \mathrm{~mm}$. Petioles from pak choi were tested separately and were cut into transverse slices $10 \mathrm{~mm}$ thick. Rutabaga roots and kohlrabi tubers were peeled and cut into sticks $15 \times 15 \times 60 \mathrm{~mm}$. Brussels sprouts were used whole.

Collection of volatiles. Volatiles were collected by placing $50 \mathrm{~g}$ of plant tissue into a $500-\mathrm{mL}$ glass canning jar and sealing it with a lid containing a septum. To measure volatiles induced by anaerobic conditions, jars were flushed with $\mathrm{N}_{2}$ for $30 \mathrm{~min}$ at a rate of 200 $\mathrm{mL} \cdot \mathrm{min}^{-1}$, using two 23-gauge hypodermic needles passed through the septum for inlet and outlet. Flushed jars were held in the dark at $20{ }^{\circ} \mathrm{C}$. Following $24 \mathrm{~h}$ in $\mathrm{N}_{2}$, a $0.5-\mathrm{mL}$ sample of headspace from each jar was analyzed for volatile content and a 1-mL sample was analyzed for $\mathrm{O}_{2}$ and $\mathrm{CO}_{2}$ using a gastight glass syringe. Headspace samples of $0.1 \mathrm{~mL}$ from jars containing broccoli florets were analyzed to prevent saturation of the detector due to high volatile concentrations. To measure aerobic volatile production in control samples, vegetables were sealed in jars containing air without $\mathrm{N}_{2}$ flushing and were sampled $1 \mathrm{~h}$ after sealing, as described for the anaerobic samples.

Volatile analysis. The concentrations of MT, DMDS, DMTS, and ethanol in headspace samples were analyzed on a Magnum GC-MS system (Finnigan MAT, San Jose, Calif.). Samples were injected directly onto a Supelcowax $10,60 \mathrm{~m} \times 0.53 \mathrm{~mm}$ column with a film thickness of $1 \mu \mathrm{m}$ (Supelco, Bellefonte, $\mathrm{Pa}$.). The column flow rate was $10 \mathrm{~mL} \cdot \mathrm{min}^{-1}$ of $\mathrm{He}$. The transfer line and ion trap temperatures were 180 and $220{ }^{\circ} \mathrm{C}$, respectively. The column temperature was held at $40^{\circ} \mathrm{C}$ for $2 \mathrm{~min}$, increased to $120{ }^{\circ} \mathrm{C}$ at a rate of $16^{\circ} / \mathrm{min}$, increased to $240{ }^{\circ} \mathrm{C}$ at a rate of $15^{\circ} / \mathrm{min}$, and held at $240{ }^{\circ} \mathrm{C}$ for $3 \mathrm{~min}$. Compounds were identified based on retention time and mass spectrum. Quantitation was calculated based on external standards.

Respiratory gas analysis. Headspace samples $(1.0 \mathrm{~mL})$ were analyzed for $\mathrm{O}_{2}$ and 
$\mathrm{CO}_{2}$ composition using a gas chromatograph with a thermal conductivity detector. Samples were injected into a $1.9 \mathrm{~m} \times 6.4 \mathrm{~mm}$ (o.d.) CTR I column (Alltech Associates, Deerfield, Ill.) with a helium carrier flow of $50 \mathrm{~mL} \cdot \mathrm{min}^{-1}$. The oven temperature was $40^{\circ} \mathrm{C}$ and the injector and detector were held at 40 and $200{ }^{\circ} \mathrm{C}$, respectively. Oxygen levels were analyzed to check gastightness of the sealed jars. The amount of $\mathrm{CO}_{2}$ accumulating during $24 \mathrm{~h}$ in the $\mathrm{N}_{2}$ atmosphere was considered indicative of the level of anaerobic metabolism.

Statistical analysis. The experimental design was completely randomized, with three samples from each cultivar/vegetable combination. For nine vegetables, three different cultivars were tested, and for five vegetables, only one cultivar was tested. Headspace concentrations of volatiles and $\mathrm{CO}_{2}$ were analyzed using analysis of variance and means were compared using least significant difference (LSD) at $P \leq 0.05$ (Genstat 5 Committee, 1993). Control samples were not included in the statistical analysis. Correlations were calculated using SigmaPlot 4.01 (Jandel Corp., San Rafael, Calif.)

\section{Results}

Methanethiol production. The production of MT by vegetables held in anaerobic atmospheres varied with species. Broccoli florets produced higher headspace concentrations of MT than did all other vegetables tested (Fig. 1). Broccoli stems produced 25-fold less MT than did florets. Leaf blades of pak choi also produced large quantities of MT, being only $20 \%$ less than broccoli florets, but the petioles produced 60 -fold less than the leaf blades. Cauliflower florets produced very little MT, $<1 \%$ of that produced by broccoli florets, while broccoflower, a cross between broccoli and cauliflower, produced an intermediate amount of MT. Cabbages produced $10 \%$ to $50 \%$ of the amount of MT produced by broccoli florets. Savoy cabbage produced the most, followed by green and red cultivars. Kale, Brussels sprouts, and rutabagas produced $1 \%$ to $3 \%$ of the MT produced by broccoli florets, while Chinese cabbage and kohlrabi produced $<0.3 \%$. Headspace samples taken from aerobic controls contained only trace amounts of MT in all vegetables tested except for cauliflower, broccoflower, and pak choi, where none was detected.

Production of MT varied among cultivars of the vegetables tested. This was most apparent in cabbage. In green cabbage, 'Hinova' produced $>10$-fold more MT than the other two cultivars tested, and in red cabbage the unknown cultivar obtained from the local market also produced 10 -fold more than the other two red cultivars. In savoy cabbage, the sample obtained from the local market produced $\approx 500$-fold less MT than the other two cultivars. In broccoli, florets and stems of 'Paragon' and 'Arcadia' produced 3- and 5fold more MT than 'Everest', respectively. 'Floriade' and 'Siria' cauliflower produced 3and 7-fold more MT than 'Amazing', respectively. In Brussels sprouts, which produced low concentrations of MT, 'Jade Cross E' produced $>100$-fold less MT than the other two cultivars tested. No significant cultivar differences in MT production were observed in broccoflower or rutabaga.

Sulfide production. Dimethyl disulfide production by anaerobic Brassica vegetables was not significantly correlated with MT production $(r=0.439)$. Green cabbage produced the largest quantities of DMDS, followed by savoy cabbage (60\%), broccoli (40\%), and pak choi (16\%, Fig. 1). Broccoli florets produced 5-fold more DMDS than did "stem" tissue. All other vegetables tested produced $<10 \%$ of the DMDS produced by cabbage. Aerobic controls produced $0.1 \%$ to $10 \%$ of that produced by anaerobic vegetables and ranged from 2 to $7 \mu \mathrm{mol} \cdot \mathrm{m}^{-3}$

Production of DMTS correlated well with MT production $(r=0.952)$. Although headspace concentrations of DMTS were $\approx 500$ fold less than those of MT, the relative concentration among different vegetables followed a pattern similar to that observed for MT (Fig. 1). However, quantitative differences in DMTS production were not as great as those for MT. Broccoli stems produced $\approx 50 \%$ of the quantity of DMTS produced by florets. Headspace samples taken from aerobic controls contained only trace amounts of DMTS.

Anaerobic metabolism. The concentration of $\mathrm{CO}_{2}$ produced by these vegetables when held under anaerobic conditions ranged from 1.06 to $6.60 \mathrm{~mol} \cdot \mathrm{m}^{-3}$ (Fig 2.). Vegetables consisting of flower buds (broccoli, broccoflower, and cauliflower) produced the most $\mathrm{CO}_{2}$. Ethanol accumulated to high concentrations in most vegetables and correlated well with $\mathrm{CO}_{2}$ levels $(r=0.932)$. Pak choi and kale produced the lowest amounts of ethanol among the vegetables tested. Aerobic controls for all of the vegetables tested produced only trace concentrations of ethanol. There was no apparent relationship between $\mathrm{CO}_{2}$ and $\mathrm{MT}$ production.

\section{Discussion}

Methanethiol was detected in all of the Brassica vegetables tested in this study that were held in $\mathrm{N}_{2}$, but the amounts were highly variable. Broccoliflorets produced the highest concentration of MT among the vegetables tested. Other investigators have also reported that anaerobic broccoli produced MT (Dan et al., 1997; Di Pentima et al., 1995; Forney et al., 1991; Hansen et al. 1992). Forney and Jordan

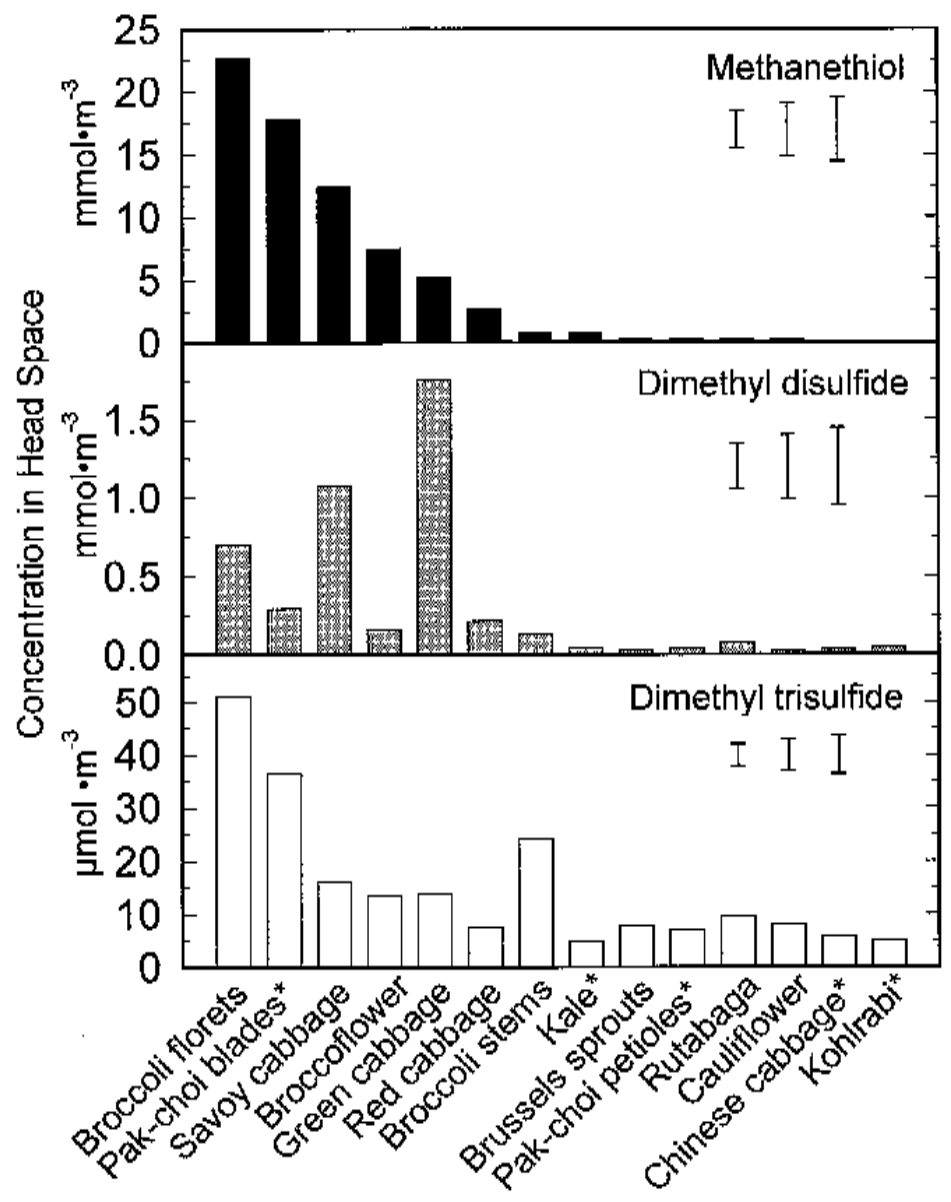

Fig. 1. Headspace concentrations of MT, DMDS, and DMTS in 500-mL jars containing $50 \mathrm{~g}$ of fresh-cut Brassica vegetables $24 \mathrm{~h}$ after being flushed with $\mathrm{N}_{2}$ and held at $20^{\circ} \mathrm{C}$ in the dark. Values for broccoli, savoy cabbage, broccoflower, green cabbage, red cabbage, Brussels sprouts, rutabaga, and cauliflower are means for nine samples with three samples each from three different cultivars. Values for pak choi, kale, Chinese cabbage, and kohlrabi (identified with an * on the figure) are means for three samples from one cultivar. Error bars, from left to right, represent $\mathrm{LSD}_{0.05}$ values for means of nine samples, means for nine plus three samples, and means for three samples. 


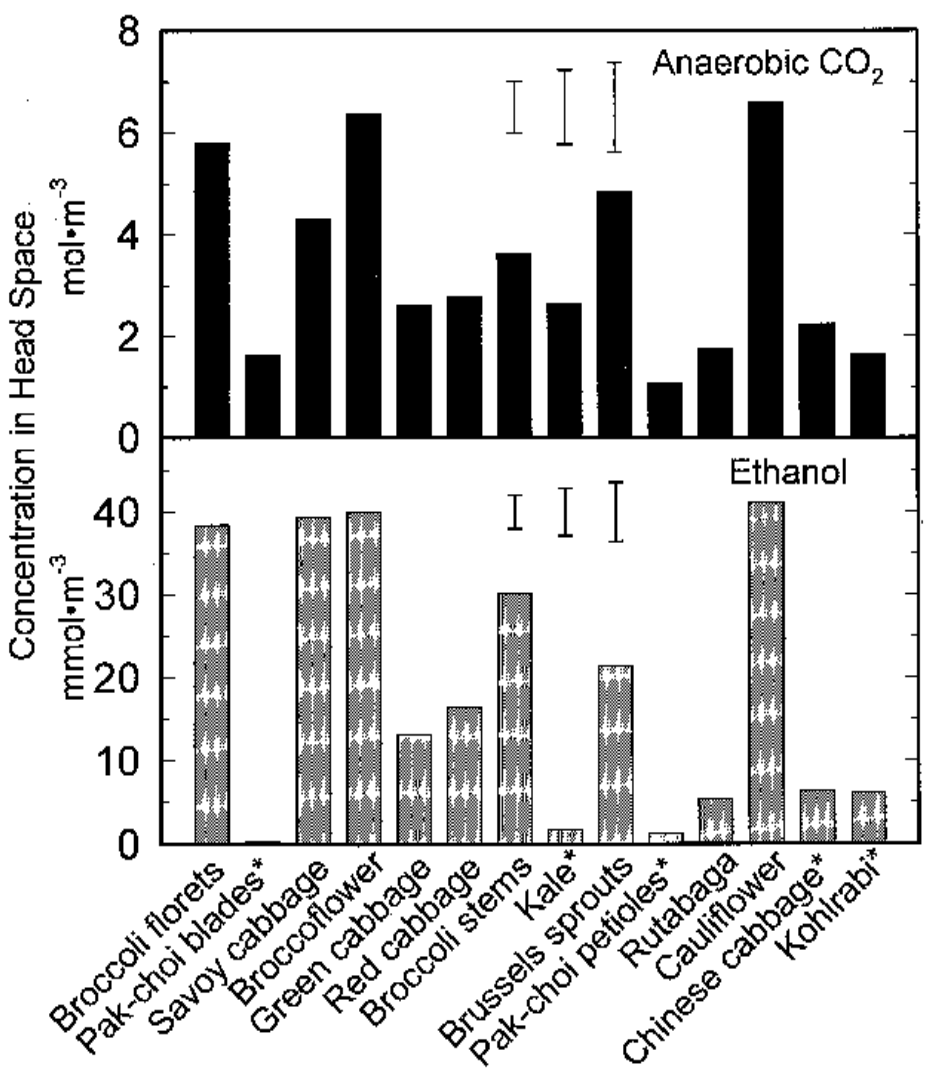

Fig. 2. Headspace concentrations of $\mathrm{CO}_{2}$ and ethanol in 500-mL jars containing $50 \mathrm{~g}$ of fresh-cut Brassica vegetables $24 \mathrm{~h}$ after being flushed with $\mathrm{N}_{2}$ and held at $20{ }^{\circ} \mathrm{C}$ in the dark. Values for broccoli, savoy cabbage, broccoflower, green cabbage, red cabbage, Brussels sprouts, rutabaga, and cauliflower are means for nine samples with three samples each from three different cultivars. Values for pak choi, kale, Chinese cabbage, and kohlrabi (identified with an * on the figure) are means for three samples from one cultivar. Error bars, from left to right, represent $\mathrm{LSD}_{0.05}$ values for means of nine samples, means for nine plus three samples, and means for three samples.

(1995) noted that MT in broccoli was produced mainly by the buds, with lesser amounts of MT evolved from stem and peduncle tissues. This is consistent with our observation that broccoli florets produced more MT than stem tissue. Additional tissues that produced significant quantities of MT included pak choi leaf blades, broccoflower florets, and shredded leaves of savoy, green, and red cabbage, indicating their potential to produce objectionable odors in anaerobic atmospheres. Brassica vegetables with less potential to produce MT include kale, Brussels sprouts, rutabaga, cauliflower, Chinese cabbage, and kohlrabi. The $\mathrm{O}_{2}$ levels used in this study were very low; less severe conditions that could develop in MAP or during postharvest handling may not induce MT and its associated off-odor in vegetables that produced low levels of MT.

Cultivars of a given vegetable varied in the production of MT and other sulfur-containing volatiles. This was especially evident in cabbage, where MT production varied 10-fold in the three cultivars tested. Chin and Lindsay (1993) also found a large variation in MT production among 38 cabbage cultivars, with concentrations ranging from 0 to $45 \mathrm{~nL} \cdot \mathrm{L}^{-1}$ 100 min after homogenization. This inherent variation makes cultivar selection important when attempting to minimize the risk of offodors in packaged fresh vegetables.
Green tissues appeared to have a greater capacity to produce MT than nongreen tissues. This was demonstrated most dramatically with pak choi, in which dark green leaf blades produced 60-fold more MT than white petioles. Similarly, broccoli florets had the greatest capacity to produce MT, while "stems" produced lower quantities. Cauliflower, which is closely related to broccoli, but lacks chlorophyll, produced only trace amounts of MT. Broccoflower, which can be considered intermediate between broccoli and cauliflower, was also intermediate in MT production. None of the vegetables lacking chlorophyll, including kohlrabi, rutabaga, cauliflower, and pak choi petioles, produced significant quantities of MT. However, several that contained chlorophyll, including kale, Brussels sprouts, and Chinese cabbage, produced very little MT. Thus, the basis of these tissue-specific differences in MT production is not clear and warrants further investigation.

Several possible mechanisms for the production of MT in broccoli have been suggested. These include the enzymatic conversion of the amino acids L-methionine and Smethylcysteine to MT (Dan et al., 1997; Di Pentima et al., 1995; Saini et al., 1995). Di Pentima et al. (1995) demonstrated that a cellfree system of fresh broccoli produced MT when these amino acids were added. How- ever, MT was produced from cell-free systems from broccoli held in both aerobic and anaerobic atmospheres, and the induction of enzymes that produce MT has not been demonstrated (Dan et al., 1997; Di Pentima et al., 1995). Production of MT may be limited by availability of substrate. Atmospheres that induced MT increased the free amino acid content of broccoli (Di Pentima, 1995), as well as the leakiness of broccoli tissues (Dan et al., 1997). Different rates of MT production among vegetables may reflect their different levels of enzymes and/or substrates.

General metabolic activity, reflected by $\mathrm{CO}_{2}$ production, was not associated with the ability of the vegetables to produce MT. Similarly, ethanol production was a good indicator of anaerobic respiration, with the exception of pak choi and kale, but not of MT production. However, vegetables with high metabolic activity are more likely to develop anaerobic atmospheres by depleting $\mathrm{O}_{2}$ when the supply is limited. This may explain why vegetables with high metabolic rates and high ability to produce MT, such as broccoli, are most likely to develop anaerobically induced off-odors.

Production of DMDS was not well correlated with MT production and was the only compound measured that was produced in significant quantities in aerobic controls. Production can occur as a result of the oxidation of MT (Chin and Lindsay, 1994a, 1994b; Dan et al., 1997). This process may contribute to DMDS production, but DMDS can also be produced independently of MT. Chin and Lindsay (1994b) suggest that DMDS is produced in cabbage by the dehydration and disproportionation of methanesulfenic acid. Both of these two mechanisms for DMDS formation may be responsible for DMDS production in Brassica vegetables, but to different degrees in different vegetables, thus explaining the poor correlation between MT and DMDS production.

Concentration of DMTS in the headspace was correlated with MT production. Several mechanisms by which DMTS might be produced in disrupted cabbage have been described (Chin and Lindsay, 1994a, 1994b). These include the reaction of 1) methyl methanethiosulfinate and hydrogen sulfide, 2) MT and hydrogen sulfide in the presence of ascorbate and Fe (III), and 3) MT, hydrogen peroxide, and hydrogen sulfide. In the presence of ascorbate and Fe (III), MT was converted to DMTS at a rate $10 \times$ greater than was DMDS (Chin and Lindsay, 1994a). Since DMTS concentrations in our study were correlated with MT concentrations following the 24-h anaerobic incubation, a significant portion of DMTS may have been formed from MT through these latter reactions.

All three compounds (MT, DMDS, and DMTS) can contribute to off-odors in Brassica vegetables that are held in anaerobic atmospheres. Of these three, MT is of greatest concern because of its low odor threshold $\left(0.02 \mathrm{~nL} \cdot \mathrm{L}^{-1}\right)$ (Hansen et al., 1992), high volatility, and high rate of production in many of the Brassica vegetables; DMTS has a similar odor threshold of $0.01 \mathrm{~nL} \cdot \mathrm{L}^{-1}$ (Hansen et al., 
1992) and could also contribute to the objectionable odor. The odor threshold of DMDS is $\approx 1000$-fold greater than that of MT or DMTS and therefore should contribute the least of these three compounds to anaerobically induced off-odors. Results from this study give preliminary indications of the risk of different fresh-cut Brassica vegetables developing offodors under anaerobic conditions that may develop in MAP or during postharvest handling. However, because of variation among cultivars, specific cultivars should be tested for their potential to produce objectionable odors.

\section{Literature Cited}

Ballantyne, A., R. Stark, and J.D. Selman. 1988 Modified atmosphere packaging of broccoli florets. Intl. J. Food Sci. Technol. 23:353-360.

Chin, H.W. and R.C. Lindsay. 1993. Volatile sulfur compounds formed in disrupted tissues of different cabbage cultivars. J. Food Sci. 58:835841.

Chin, H.W. and R.C. Lindsay. 1994a. Ascorbate and transition-metal mediation of methanethiol oxidation to dimethyl disulfide and dimethyl trisulfide. Food Chem. 49:387-392.

Chin, H.W. and R.C. Lindsay. 1994b. Mechanisms of formation of volatile sulfur compounds following the action of cysteine sulfoxide lyases. J. Agr. Food Chem. 42:1529-1536.

Dan, K., S. Todoriki, M. Nagata, and I. Yamashita. 1997. Formation of volatile sulfur compounds in broccoli stored under anaerobic condition. J. Jpn. Soc. Hort. Sci. 65:867-875.

Di Pentima, J.H., J.J. Ríos, A. Clemente, and J.M Olías. 1995. Biogenesis of off-odor in broccoli storage under low-oxygen atmosphere. J. Agr. Food Chem. 43:1310-1313.

Forney, C.F. and M.A. Jordan. 1995. Methanethiol production by Brassica vegetables held in anaerobic atmospheres. HortScience 30:823. (Abstr.)

Forney, C.F., J.P. Mattheis, and R.K. Austin. 1991.
Volatile compounds produced by broccoli under anaerobic conditions. J. Agr. Food Chem. 39:2257-2259.

Forney, C.F. and R.E. Rij. 1991. Temperature of broccoli florets at time of packaging influences package atmosphere and quality. HortScience 26:1301-1303.

Genstat 5 Committee. 1993. Genstat 5 release 3 reference manual. Clarendon Press, Oxford, U.K.

Hansen, M., R.G. Buttery, D.J. Stern, M.I. Cantwell, and L.C. Ling. 1992. Broccoli storage under low-oxygen atmosphere: Identification of higher boiling volatiles. J. Agr. Food Chem. 40:850852

Kasmire, R.F., A.A. Kader, and J.A. Klaustermeyer. 1974. Influence of aeration rate and atmospheric composition during simulated transit on visual quality and off-odor production by broccoli. HortScience 9:228-229.

Saini, H.S., J.M. Attieh, and A.D. Hanson. 1995. Biosynthesis of halomethanes and methanethiol by higher plants via a novel methyltranferase reaction. Plant Cell Environ. 18:1027-1033. 